\title{
A SPATIAL ANALYSIS OF CHANGES IN RECREATIONAL FISHING PRESSURE ON THE CENTRAL COAST OF CALIFORNIA SUBSEQUENT TO MPA IMPLEMENTATION
}

\author{
A Thesis \\ presented to \\ the Faculty of California Polytechnic State University, \\ San Luis Obispo \\ In Partial Fulfillment \\ of the Requirements for the Degree \\ Master of Science in Biological Sciences
}

by Morgan Ivens-Duran

August 2014 
(C) 2014

Morgan Ivens-Duran

ALL RIGHTS RESERVED 
TITLE:

AUTHOR:

DATE SUBMITTED:

COMMITTEE CHAIR:

COMMITTEE MEMBER:

COMMITTEE MEMBER:
A spatial analysis of changes in recreational fishing pressure on the central coast of California subsequent to MPA implementation

Morgan Ivens-Duran

August 2014

Dean Wendt, $\mathrm{PhD}$

Professor of Biological Sciences

Elizabeth Lowham, PhD

Professor of Political Science

Royden Nakamura, PhD

Professor of Biological Sciences 


\section{ABSTRACT}

A spatial analysis of changes in recreational fishing pressure on the central coast of California subsequent to MPA implementation Morgan Ivens-Duran

Marine Protected Areas (MPAs) are implemented to address a variety of management concerns, including conservation and restoration of fisheries, but few studies assess how MPAs affect regional fishing patterns. Previous research suggests effort will intensify at MPA edges, but few datasets include sufficient pre-implementation data to quantify how MPAs alter fishing effort. We used recreational fisheries data collected by scientific observers aboard Commercial Passenger Fishing Vessels that target nearshore fish species, primarily rockfish. We assessed shifts in the spatial distribution of fishing effort over a 10-year period that includes pre- and postimplementation observations of the California MPA network along the Central Coast. We visually depict fine-scale annual fishing pressure, calculate total regional effort, and identify changing hot spots of fishing activity. While we found no evidence for "fishing the line", MPA implementation was associated with changes in regional fishing patterns, including contraction of fishing effort away from the northern extent of the region and increased effort intensity in some pre-MPA fishing hotspots. Fishing effort redistribution should be considered in future management decisions regarding California's MPA network. 


\section{ACKNOWLEDGMENTS}

Thanks to Eric Anderson, Paul Carvahlo, Jenny Green, Nate Hall, David Hernandez, Leslie Longbach, Natasha Meyers-Cherry, Erin Nakada, Larissa Ormande, James Perrin, Heather Price, Kyle Purdy, Dave Rassmussen, Steve Rienecke, and Cate Webster for their work with the Cal Poly CPFV Observer Program. Andrew Schaffner from the Cal Poly Statstics Department provided invaluable assistance with developing the data analysis methods used in this study. Russell White at the Cal Poly Kennedy Library Data Studio provided help with the ArcGIS analysis, and Brian Zelenke at Cal Poly assisted with the MATLAB analysis as well as providing general technical assistance. Deborah Aseltine-Neilson and Jana Robertson from the California Department of Fish \& Wildlife provided additional data. We would especially like to thank the staff, captains, and crew of Virg's Sportfishing, Patriot Sportfishing, and Central Coast Sportfishing, who allowed us to observe their fishing trips and without whom this project would not have been possible. This research was supported by California Sea Grant, the California Polytechnic State University College of Science and Math, the David and Lucile Packard Foundation, the Resources Legacy Fund Foundation, the California Coastal Conservancy, and the California Ocean Protection Council. 
LIST OF TABLES

LIST OF FIGURES

CHAPTER

I. INTRODUCTION

II. METHODS

Study Site and Management Context

Data Collection

Calculation of Fishing Effort

Modeling Regional Fishing Effort

Fishing Effort with Distance to MPAs

CPFV Operator Focus Group

III. RESULTS

Total Regional Fishing Effort

Regional Shifts in Fishing Effort

Fishing Effort with Distance to MPAs

IV. DISCUSSION

Total Regional Fishing Effort

Regional Shifts in Fishing Effort

20

Fishing Effort with Distance to MPAs

Management Implications and Future Work 


\section{APPENDICES}

I. Z-scores for average pre (a) and post MPA (b) fishing effort. Yellow represents pixels with higher effort than the map-wide average, while green represents pixels with lower effort than the map-wide average. The statistical significance of the deviation from the map-wide average is represented by the shade of green or yellow. Dark green and bright yellow represent a statistically significant change at $\alpha=0.01(\mathrm{abs}(Z)>2.575829)$, medium-intensity green and yellow represent a statistically significant change at 0.01 $\leq \alpha \leq 0.05$ (1.959963 $<\operatorname{abs}(Z)<2.575829)$, pale green and yellow represent no significant change at the $\alpha \leq 0.05$ level $(\operatorname{abs}(Z)<$ 1.959963), and white represents pixels with effort equal to the map-wide average

II. Standard deviation of mean fishing effort estimates. Shown for the pre (a) and post (b) MPA time periods, as well as the difference between pre and post effort (c); calculated across all years and bootstraps. Darker purple represents higher standard deviation values 


\section{LIST OF TABLES}

Table

1. Dataset composition: observed drops. The estimated annual proportion of observed drops, calculated as the number of observed drops divided by the estimated total number of drops. Since CPFV logbooks submitted to the CA DFW do not include the number of fishing drops that occurred per trip, the total regional number of drops was estimated by multiplying the number of trips that occurred in the region by the average number of drops per observed trip that year

2. Total Regional Effort Comparisons. $\mathrm{P}$ values for all 45 comparisons of total regional effort (averaged across bootstraps) are shown.

Values in italics are significant at $\alpha=0.05$, while non-italicized bolded values in black font are significant at $\alpha=0.0011$ after applying a Bonferroni correction for multiple comparisons. Values in grey represent non-significant comparisons $(p>0.1)$ 
Figure

\section{LIST OF FIGURES}

1. Map showing the relative position of Marine Protected

Areas along the south-central coast of California. All of the

MPAs shown, other than the Cambria SMCA, prohibit the recreational take of rockfish (Sebastes) species

2. Estimated regional fishing effort from 2003 to 2012. Grey bars (2003 - 2006) represent pre-MPA implementation effort, the white bar (2007) represents the year of MPA establishment, and black bars (2008 - 2012) represent post-MPA implementation effort. Error bars represent $\pm 1 \mathrm{SE}$. Lines represent average effort prior to and after MPA establishment. Mean post-MPA effort (grey line) was significantly greater than mean pre-MPA effort (black line; $p<<0.01)$. Inter-annual statistical comparisons are included in Table 2

3. Regional fishing effort distribution and intensity prior and subsequent to MPA implementation, and the difference in regional fishing effort between these two time periods. Mean pre-MPA (a) and post-MPA (b) regional fishing effort is depicted in units of angler*minutes, where dark blue represents areas of no fishing effort, green represents areas with some fishing effort, and yellow represents areas with high fishing effort. The z-score of the change in mean effort (angler*minutes) at each pixel from pre to post MPA implementation (c) is indicated by the color and color intensity. Blue pixels represent areas where mean effort significantly decreased from the pre to post time period, red pixels represent areas where mean effort significantly increased from the pre to post time period, and grey pixels represent areas where there was little or no change in mean effort between these two time periods. Dark blue and red represent a statistically significant change at $\alpha=0.01(\mathrm{abs}(Z)>2.575829)$ and medium-intensity blue and red represent a statistically significant change at $0.01 \leq \alpha \leq 0.05(1.959963<\operatorname{abs}(Z)<2.575829)$

4. Changes in log(effort) with distance to MPA edges. Pre-MPA implementation effort is shown in blue, and post-MPA effort is shown in red. Relationships are shown for the following MPAs: Piedras Blancas (a), White Rock (b), Point Buchon (c), and Vandenberg (d) MPAs. There was no significant effect of distance to MPA on log(effort) for any MPA ( $p>0.1)$ 


\section{INTRODUCTION}

Marine Protected Areas (MPAs) are increasingly used to manage fisheries and ecosystems, and synthetic analyses show increases in the biomass, density, and size of targeted species within MPA boundaries (Halpern and Warner 2002, Lester et al. 2009, Edgar et al. 2014). Spillover of adult fishes from these protected areas can benefit local fisheries by increasing the density and size of target species in fishable waters near MPAs (Roberts et al. 2012, Goñi et al. 2008, Follesa et al. 2011). While the degree of spillover depends on the trophic level of targeted catch and nearby fishing intensity (Ashworth et al. 2005), spillover can occur 100s of meters from a reserve boundary (Russ and Alcala 1996, Harmelinvivien et al. 2008, Halpern et al. 2010, Russ and Alcala 2011). Although the spillover of adult fishes can boost local fisheries, MPAs can also displace fishing activities from near-port fishing grounds, imposing economic costs on fishers unless offset by favorable market factors (Hannesson 1998, Stevenson et al. 2013). While the response of individual fishers will vary based on the distribution and behavior of target species (Horta e Costa et al. 2013), fishers often concentrate their effort near the borders of newly established MPAs (Murwaski et al. 2005, Powers and Abeare 2009, Stelzenmüller et al. 2009). Some studies have shown this "fishing the line" behavior can increase catch (Stobart et al. 2009, La Mesa et al. 2011), but others warn that intensifying effort near reserve edges can impede the very spillover benefits fishers are hoping to harness (Goñi et al. 2010, McClanahan and Kaunda-Arara 2012). As 
implementation of MPAs increases worldwide, it is imperative to understand how MPAs affect the distribution of fishing effort and local fishing economies (Sen 2010). Logbooks collected by management agencies are a crucial source of data on fishing activity, however fishing locations are typically reported at a coarse spatial resolution, preventing hyper-local assessments of fishing effort (Murwaski et al. 2005). Spatially explicit data on fishing effort is critical for understanding the dynamics of fisheries that target organisms with small home ranges occupying scattered habitats, since less spatially resolved information may not capture slight shifts in effort hotspots driven by small-scale fishing closures.

In this study, we use independently collected fine-scale spatial data on recreational fishing trips targeting rockfish (Sebastes spp.), lingcod (Ophiodon elongatus), and associated species along the south-central coast of California. These trips dominate the Commercial Passenger Fishing Vessel (CPFV) industry at both ports in this region: Port San Luis and Morro Bay (CA OST 2012). We quantify how implementation of MPAs on the central coast of California has affected regional fishing patterns. By constructing maps showing the spatial distribution and intensity of recreational fishing trips over an 10-year period spanning both pre- and post-MPA implementation, we aim to better understand how MPAs have altered regional fishing dynamics. We address the following questions over the period from 2003 to $2012: 1$. How has total regional fishing effort changed; 2 . How has the distribution and intensity of regional fishing effort shifted; and 3. How has fishing effort changed near MPAs? 


\section{METHODS}

Study Site and Management Context

The subtidal waters along the central coast of California, USA are characterized by temperate rocky reefs that support kelp forest communities and associated species such as rockfishes (Sebastes spp.) and lingcod (Ophiodon elongates). Recreational fishing trips on the central coast commonly target Sebastes species, and dominate the south-central California CPFV fleet in Morro Bay and Port San Luis (CA OST 2012).

The local rockfish CPFV fleet on the south-central coast of California is subject to both federal and state management. In 2002 the federal government established Rockfish Conservation Areas (RCA) along the west coast of the United States seaward of 40 fathoms (Federal Regulations $§ 660.360$ 3iA4) in response to declining rockfish stocks. The RCAs closed off vast portions of fishable habitat to the south central California CPFV fleet. While no fine-scale spatial data exist on regional fishing effort prior to RCA establishment, it is likely the vast spatial closure substantially affected regional fishing effort.

Prior to 2002, local CPFV operators fished almost exclusively in waters now protected within the RCAs, and only fished in nearshore waters shallower than 40 fathoms when weather conditions prevented fishing farther offshore (CPFV Focus Group 2014).

The federally mandated spatial closures were augmented in 2007 when the California Department of Fish and Wildlife (CADFW) established 28 Marine 
Protected Areas (MPAs) along the central coast. Along the southern portion of the central coast, MPAs were established at Piedras Blancas, Cambria, Morro Bay, Point Buchon, and Vandenberg Air Force Base (Figure 1). Other than the Cambria SMCA, all of these MPAs prohibit the recreational take of Sebastes species and all species of groundfish (CA DFW 2013).

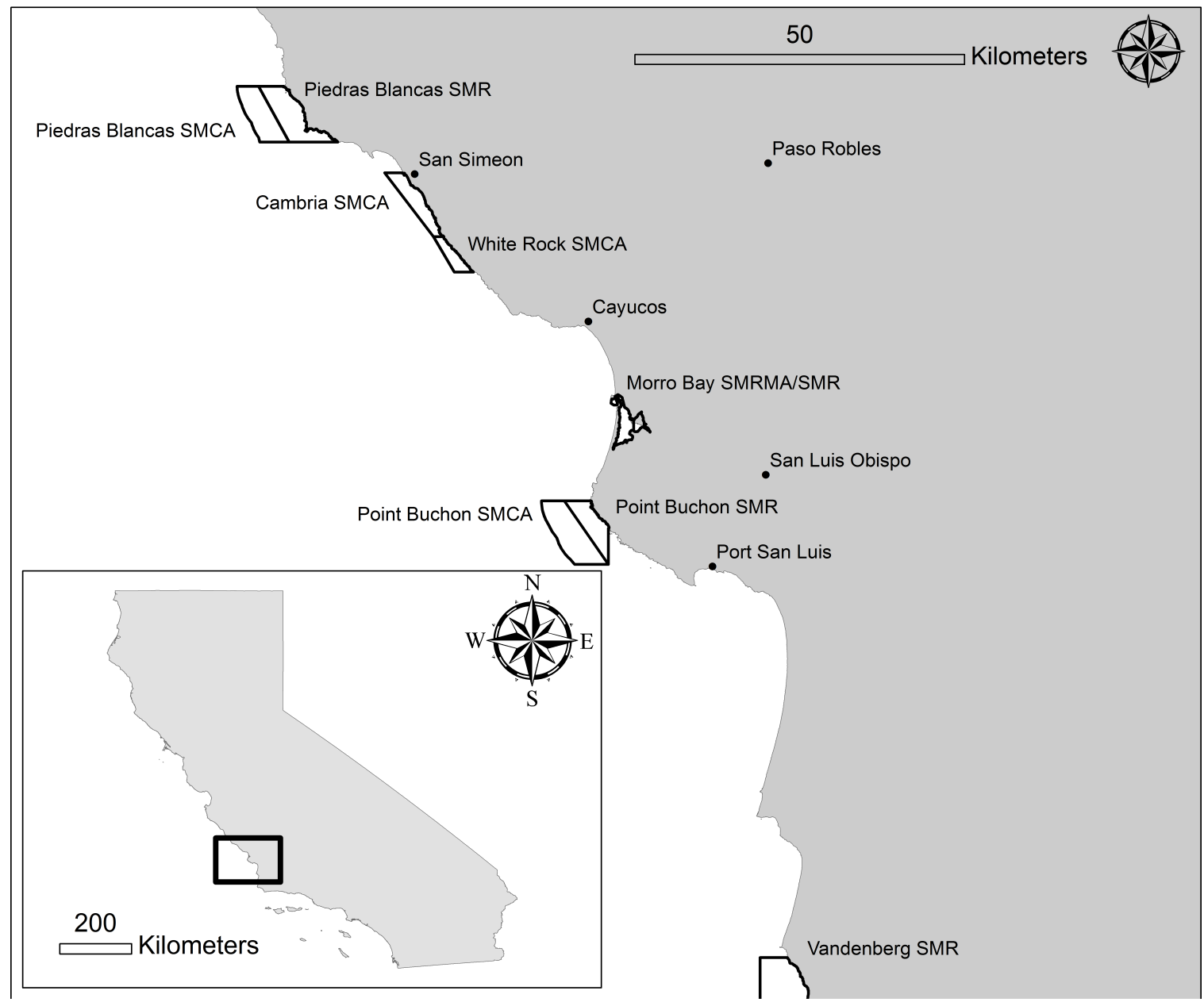

Figure 1. Map showing the relative position of Marine Protected Areas along the south-central coast of California. All of the MPAs shown, other than the Cambria SMCA, prohibit the recreational take of rockfish (Sebastes) species. 


\section{Data Collection}

Researchers from California Polytechnic State University, San Luis Obispo have collected data on recreational hook-and-line fishing trips targeting rockfishes (Sebastes spp.) since 2003. The observed trips represent a subset of the CPFV activity originating from Port San Luis and Morro Bay. The fishing activity during each trip is comprised of multiple drops. The length of each drop varies according to weather conditions, the rate at which fish are landed on the boat, and the discretion of the captain. The drops included in our analysis range from $1-297$ minutes in length, with an average drop length of $18.9 \pm 13.8$ minutes (mean $\pm S D ; n=5467$ ). Observers also record the GPS coordinates of each drop, the total number of anglers on the trip, and all fish caught by observed anglers (for further detail, see Stephens et al. 2006).

\section{Calculation of Fishing Effort}

In this study, "fishing effort" is calculated as:

$$
E_{D}=N^{*} T
$$

where $E_{D}$ is the fishing effort per drop, $\mathrm{N}$ is the total number of fishers on that trip, and $\mathrm{T}$ is the number of minutes spent fishing during that drop. When the total number of anglers on the trip was not recorded in the field, we obtained the information from CA Department of Fish and Wildlife records.

\section{Modeling Regional Fishing Effort}

We conducted spatial analysis using R (v 3.0.3), Matlab ( $v$ 2014a) and ArcGIS (v 10.2). In R, we used kernel density estimation (KDE) with a Gaussian 
kernel to estimate the probability of a drop occurring in a given location based on the spatial distribution of the observed drops. We calculated the proportion of observed drops per season by dividing the number of observed drops by the total number of drops that could have been observed (Table 1). Since the logbooks submitted by boat captains to CA DFW do not include the number of drops that occurred during each fishing trip, we estimated the total number of drops per season by multiplying the total number of trips targeting the rockfish-lingcod complex in the study area by the average number of drops on observed trips. We used multivariate cluster analysis on drop locations to identify localized fishing areas and their size within the study region. We then estimated fishing area size using the total variance in the latitude and longitude coordinates within each localized fishing area, and set the KDE bandwidth to be the square root of this variance $(h=0.0155)$. We set the KDE prediction pixel size based on conversations with local boat captains, during which we determined the average area covered by a single drop was $800 \mathrm{~m}^{2}$, or 0.00745 decimal degrees at $34^{\circ}$ latitude. 


\begin{tabular}{|r|r|r|r|}
\hline Year & \multicolumn{2}{|l|}{$\begin{array}{l}\text { Number of } \\
\text { Observed Drops }\end{array}$} & \multicolumn{2}{l|}{$\begin{array}{l}\text { Number of Drops } \\
\text { of Observed Drops }\end{array}$} \\
\hline 2003 & 2731 & 614 & 0.225 \\
\hline 2004 & 3580 & 1202 & 0.336 \\
\hline 2005 & 2313 & 469 & 0.203 \\
\hline 2006 & 3556 & 691 & 0.194 \\
\hline 2007 & 3329 & 575 & 0.173 \\
\hline 2008 & 4114 & 258 & 0.063 \\
\hline 2009 & 4188 & 160 & 0.038 \\
\hline 2010 & 3790 & 726 & 0.192 \\
\hline 2011 & 4239 & 434 & 0.102 \\
\hline 2012 & 3787 & 338 & 0.089 \\
\hline
\end{tabular}

Table 1: Dataset composition: observed drops. The estimated annual proportion of observed drops, calculated as the number of observed drops divided by the estimated total number of drops. Since CPFV logbooks submitted to the CA DFW do not include the number of fishing drops that occurred per trip, the total regional number of drops was estimated by multiplying the number of trips that occurred in the region by the average number of drops per observed trip that year.

We used splines to estimate fishing effort at each KDE prediction pixel. Using the drop density estimates, we distributed the total number of drops for each season over the entire study area to obtain the estimated number of drops in each pixel. We then multiplied the estimated distribution of drops by the estimated effort to calculate the annual estimated effort for each KDE prediction pixel. 
To assess uncertainty in the aforementioned estimates, bootstrapping was used for each year in the effort analysis. We re-sampled the data with replacement and re-fit the model 10,000 times. The mean effort values across bootstraps were used as a pixel-by-pixel estimate of effort, and the standard deviation across bootstraps was used to quantify pixel-by-pixel uncertainty.

To visualize the results of the above analysis, the pixel-by-pixel estimated effort values for each year were then exported into ArcGIS, projected into NAD 1983 UTM Zone 10N, and re-interpolated using the Natural Neighbor tool in Spatial Analyst (pixel size $=400 \mathrm{~m}$ ).

For computational efficiency, we used Matlab to assess changes in the average distribution of fishing effort prior (2003 - 2006) and subsequent (2008 2012 ) to MPA implementation. We a priori removed 2007 , the first year of MPA implementation, from this analysis because the MPA restrictions were not strictly enforced (CA Department of Fish and Wildlife, personal communication) and we expected fishing during this transitional year to represent a blend of typical pre and post-MPA patterns. To compare effort values on a pixel-by-pixel basis across these two time periods, we used the annual bootstrap outputs to construct a four-dimensional array where the first two dimensions contained the effort values at specified latitude and longitude coordinates ( 43 X 197), the third dimension included output from each bootstrap calculation $(10,000)$, and the fourth dimension specified the year (2003 - 2012). This four-dimensional array was then split into two sub-arrays, one with data from 2003 - 2006 and one with 
data from $2008-2012$. To preserve the error estimation of our bootstrapping, we first took the mean across the fourth dimension (year) to calculate the mean effort values for each bootstrap in the two time periods, followed by the mean across the third dimension (bootstrap) to calculate a single mean effort value for each pixel in both time periods as well as a standard deviation and z-score for each pixel.

To visualize the results of the above analysis, the pixel-by-pixel mean effort, standard deviation of mean effort, and z-scores for both time periods as well as the difference between those time periods were then exported into ArcGIS, projected into NAD 83 UTM Zone 10N, and re-interpolated using the Natural Neighbor tool in Spatial Analyst (pixel size $=400 \mathrm{~m}$ ). Fishing Effort with Distance to MPAs

To quantify how fishing effort has changed at varying distances from MPA edges over time, we constructed rasters in ArcGIS with values equal to the distance from each pixel to the closest border of the MPAs at Piedras Blancas (SMR and SMCA combined), White Rock, Point Buchon (SMR and SMCA combined), and Vandenberg. We did not perform this analysis with the Cambria SMCA since the MPA allows for the recreational take of rockfishes and we would not expect this closure to affect fishing effort. We then paired these distance rasters with the locations and effort associated with all of the drops in our dataset. Due to the large number of drops with effort values of zero, we log transformed our effort values prior to analysis $(\log (x+1))$. We used linear regression to assess 
the impact of MPA status (prior or subsequent to MPA establishment), distance to each MPA boundary, and the interaction between MPA status and distance to MPA on the log-transformed fishing effort of all drops within a $1 \mathrm{~km}$ radius of each MPA. To flexibly fit the data, we included $6^{\text {th }}$ order polynomials for distance to MPA and the interaction between each of those polynomials and MPA status. We used joint factor tests to determine if there was a significant effect of any of these factors on the log-transformed fishing effort values while minimizing Type I error from multiple comparisons.

\section{CPFV Operator Focus Group}

In order to triangulate the patterns observed in the above analysis and to better understand the observed shifts in fishing effort, we conducted a focus group with four CPFV operators whose trips we observed for this study in accordance with Cal Poly Human Subjects Research Guidelines (approved 5/21/14). CPFV operators were asked to compare their recollection of average pre- and post-MPA fishing hotspots with the output from the above analysis, and describe the underlying reasons for inter-annual changes in the distribution and intensity of fishing effort. 


\section{RESULTS}

Total Regional Fishing Effort

Over the course of this study, regional fishing effort fluctuated between years, with a minimum value of 1.015 million angler-minutes in 2003 and a maximum value of 1.904 million angler-minutes in 2008 (Figure 2). On average, regional fishing effort significantly increased from 1.473 million angler-minutes prior to MPA implementation to 1.666 million angler*minutes after MPA implementation in $2007(p<0.001)$. Total regional effort varied significantly among years (Table 2). Regional effort in 2003 was significantly different from effort in all other years, and regional effort in 2007 was not significantly different from any pre-MPA year other than 2003. 


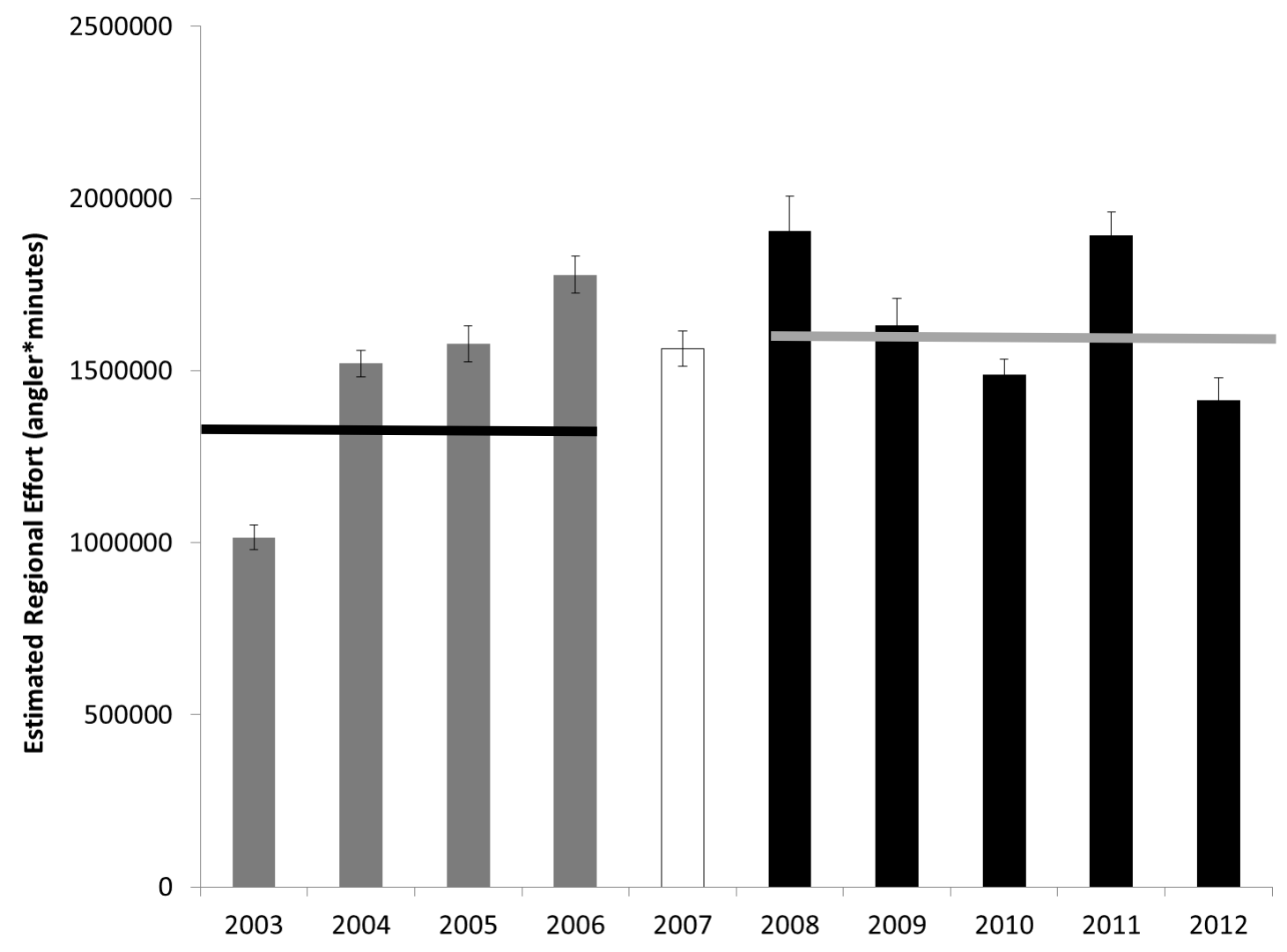

Figure 2. Estimated regional fishing effort from 2003 to 2012. Grey bars (2003 2006) represent pre-MPA implementation effort, the white bar (2007) represents the year of MPA establishment, and black bars $(2008-2012)$ represent postMPA implementation effort. Error bars represent $\pm 1 \mathrm{SE}$. Lines represent average effort prior to and after MPA establishment. Mean post-MPA effort (grey line) was significantly greater than mean pre-MPA effort (black line; $p<<0.01$ ). Interannual statistical comparisons are included in Table 2. 


\begin{tabular}{|c|c|c|c|c|c|c|c|c|c|}
\hline & 2004 & 2005 & 2006 & 2007 & 2008 & 2009 & 2010 & 2011 & 2012 \\
\hline 2003 & $<0.001$ & $<0.001$ & $<0.001$ & $<0.001$ & $<0.001$ & $<0.001$ & $<0.001$ & $<0.001$ & $<0.001$ \\
\hline 2004 & & 0.374 & $<0.001$ & 0.528 & $<0.001$ & 0.217 & 1.426 & $<0.001$ & 1.995 \\
\hline 2005 & & & 0.00842 & 1.180 & 0.00372 & 0.602 & 1.808 & $<0.001$ & 1.998 \\
\hline 2006 & & & & 1.996 & 0.242 & 1.885 & 2.000 & 0.218 & 2.000 \\
\hline 2007 & & & & & 0.00225 & 0.482 & 1.713 & $<0.001$ & 1.995 \\
\hline 2008 & & & & & & 1.973 & 2.000 & 1.168 & 2.000 \\
\hline 2009 & & & & & & & 1.880 & 0.0140 & 1.994 \\
\hline 2010 & & & & & & & & $<0.001$ & 1.900 \\
\hline 2011 & & & & & & & & & 2.00 \\
\hline 2012 & & & & & & & & & \\
\hline
\end{tabular}

Table 2: Total Regional Effort Comparisons. P values for all 45 comparisons of total regional effort (averaged across bootstraps) are shown. Values in italics are significant at $\alpha=0.05$, while non-italicized bolded values in black font are significant at $\alpha=0.0011$ after applying a Bonferroni correction for multiple comparisons. Values in grey represent non-significant comparisons $(p>0.1)$.

\section{Regional Shifts in Fishing Effort}

The spatial distribution and intensity of fishing effort shifted substantially between $2003-2006$ and $2008-2012$ (Figure 3). Prior to MPA implementation, the CPFV fleet fished intensely inside the areas that became the Piedras Blancas and Point Buchon MPAs, and regional effort was distributed fairly evenly in suitable habitat along the coast between Ragged Point and Point Purisma (a). CPFV drops also occurred regularly just outside the Port San Luis Harbor. Subsequent to MPA implementation, there was an order of magnitude decrease in fishing effort at the northern end of the region, with fewer drops occurring north of San Simeon and the Piedras Blancas MPA (b). Despite the two new hotspots in this area (c), fishing effort decreased from 392,841 angler ${ }^{\star}$ minutes to $36,162.7$ angler*minutes between the pre and post-MPA time periods. Fishing intensity 
also increased at the northern and southern edges of the Point Buchon MPAs. These changes in hotspot location and intensity are also evident in Figure 3c. Fishing effort significantly $(\alpha=0.01)$ decreased inside the Piedras Blancas and Point Buchon MPAs, around the Piedras Blancas MPA, and offshore Port San Luis Harbor. Fishing effort significantly increased to the north and south of the Point Buchon MPA, as well as offshore Point Sal and Point Purisma. Hotspots between the southern edge of the Cambria MPA and Morro Bay shifted, resulting in a mix of statistically significant increases and decreases in fishing effort ( $\alpha$ $=.05)$. 


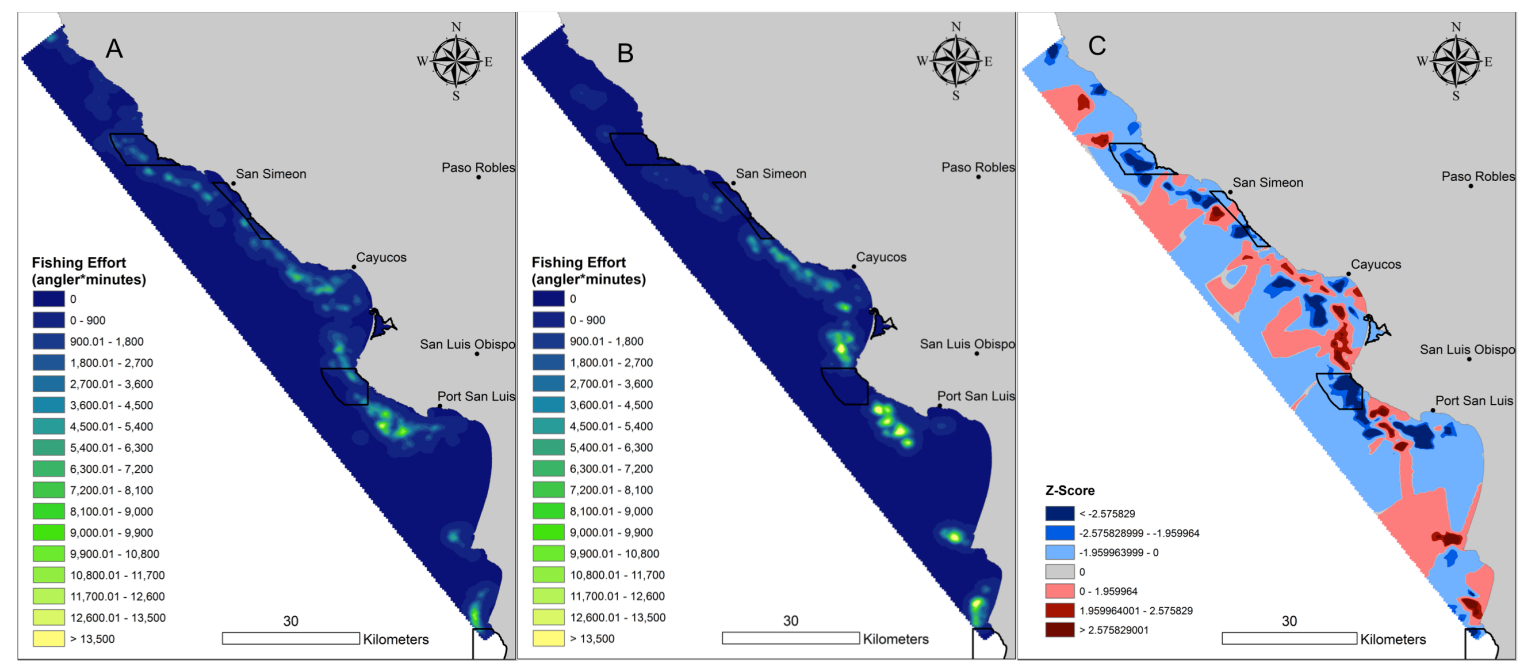

Figure 3. Regional fishing effort distribution and intensity prior and subsequent to MPA implementation, and the difference in regional fishing effort between these two time periods. Mean pre-MPA (a) and post-MPA (b) regional fishing effort is depicted in units of angler*minutes, where dark blue represents areas of no fishing effort, green represents areas with some fishing effort, and yellow represents areas with high fishing effort. The z-score of the change in mean effort (angler*minutes) at each pixel from pre to post MPA implementation (c) is indicated by the color and color intensity. Blue pixels represent areas where mean effort significantly decreased from the pre to post time period, red pixels represent areas where mean effort significantly increased from the pre to post time period, and grey pixels represent areas where there was little or no change in mean effort between these two time periods. Dark blue and red represent a statistically significant change at $\alpha=0.01(\mathrm{abs}(Z)>2.575829)$ and mediumintensity blue and red represent a statistically significant change at $0.01 \leq \alpha \leq$ $0.05(1.959963<\operatorname{abs}(Z)<2.575829)$.

Fishing Effort with Distance to MPAs

For drops that occurred within $1 \mathrm{~km}$ of the Piedras Blancas, Cambria, and White Rock MPAs, there was no significant effect of MPA status, year, or distance to the MPA border on log-transformed values of fishing effort $(p>0.1)$. Drops occurring within a 1-km band of the Point Buchon MPA showed a significant relationship between $\log ($ Effort $)$ and MPA status $(p<0.001, \mathrm{df}=14, \mathrm{~F}$ 
$=3.6624)$ and $\log$ (Effort) and year $(p<0.001, \mathrm{df}=7, \mathrm{~F}=5.1770)$, but still did not show a significant effect of distance to the MPA border on log(Effort).
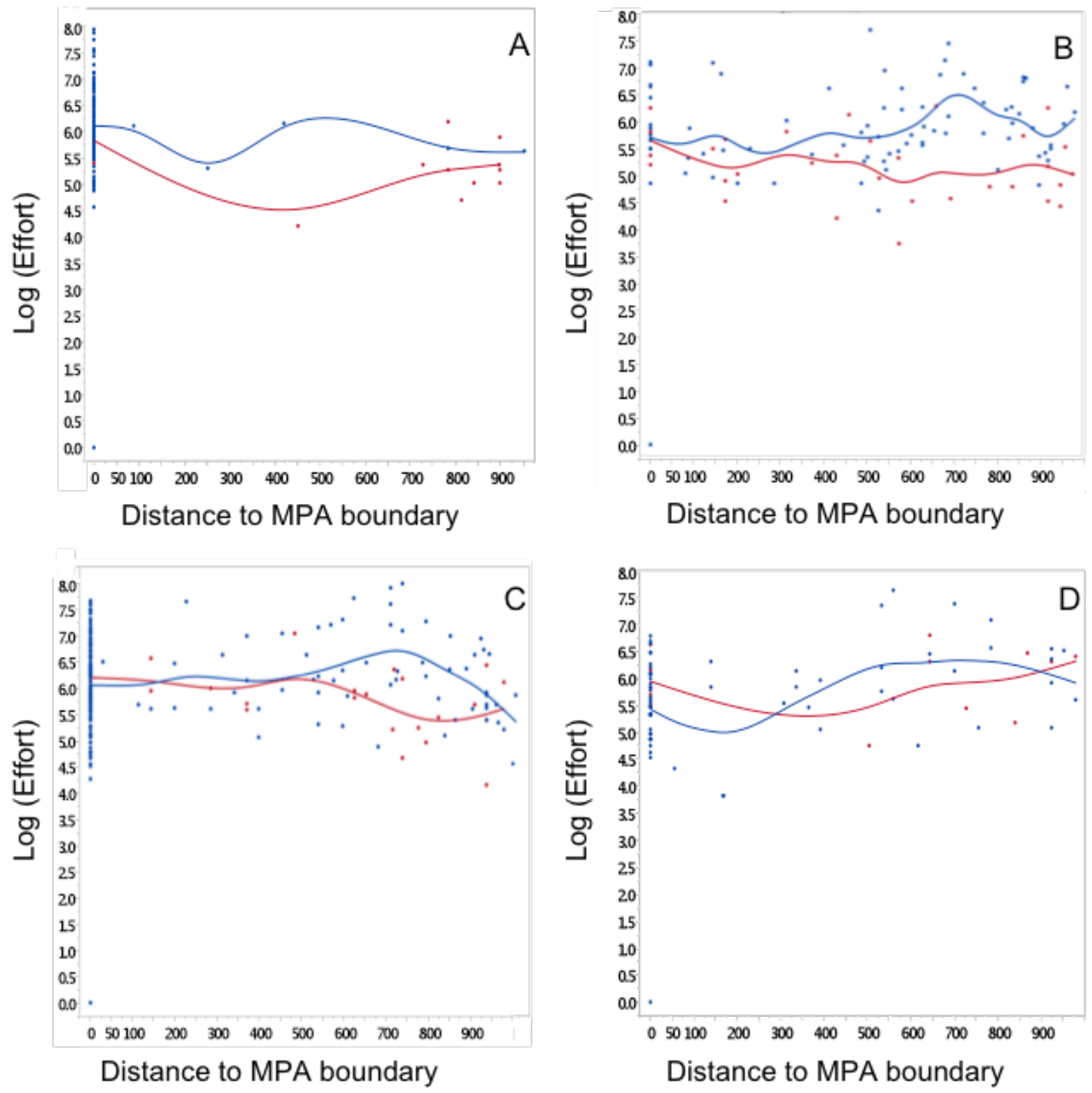

Figure 4. Changes in log(effort) with distance to MPA edges. Pre-MPA implementation effort is shown in blue, and post-MPA effort is shown in red. Relationships are shown for the following MPAs: Piedras Blancas (a), White Rock (b), Point Buchon (c), and Vandenberg (d) MPAs. There was no significant effect of distance to MPA on log(effort) for any MPA ( $p>0.1)$. 


\section{DISCUSSION}

In this study, we found implementation of a network on Marine Protected Areas on the central coast of California had a substantial impact on the post-RCA spatial distribution and intensity of fishing effort. We also found that total regional fishing effort significantly increased after MPA implementation in 2007, compared to a 4-year pre-MPA baseline. We did not see evidence for "fishing the line" behavior, likely because of the strong habitat dependency of the targeted species in this fishery. These findings have implications for ongoing adaptive management efforts in California. Future management should consider the potential for higher levels of effort in increasingly restricted fishable habitat to negatively impact stocks outside of MPA boundaries and should continue to support the collection of collaboratively collected fine-scale spatial data to monitor MPA impacts on local fisheries.

\section{Total Regional Fishing Effort}

While studies examining the impact of spatial closures on the redistribution of regional fishing effort are becoming more common (Wilcox and Pomeroy 2003, Powers and Abeare 2009, Suuronen et al. 2010, Abbot and Haynie 2012, Stevenson et al. 2012), few studies have specifically assessed changes in total regional effort following the establishment of MPAs or other closures. However, the potential negative effect of MPAs on regional fishing activity is a source of concern for fisheries scientists, managers, and local companies. Given the degree of regulation the California rockfish and lingcod 
CPFV fleet was subject to prior to 2007 , including extensive depth closures within Rockfish Conservation Areas (RCAs) established in 2002, most CPFV operators expected implementation of the Central Coast MPA network to have significant repercussions for the CPFV rockfish industry (CA OST 2012). To our surprise, despite substantial inter-annual variability, we found that total regional fishing effort significantly increased after nearshore MPAs were established in 2007 (Figure 2).

This slight but significant increase in total regional fishing effort is unlikely to be the result of recent changes in regulation of recreational rockfish take. During the study period (2003 - 2012), recreational rockfish regulations mandated no more than 2 hooks per line and a bag limit of 2 lingcod and 10 assorted rockfish per day, with the exception of a brief in-season change in 2004 that temporarily decreased the lingcod take to 1 fish and increased the minimum size limit from 24 to 30 inches (personal communication, Deborah AseltineNielsen, CA DFW). The length and composition of the recreational rockfish season varied substantially over the years, ranging from 5 to 9 months in length (CA DFW 2011). However, changes in the length of the fishing season do not appear to be the major driver of total annual fishing effort. Despite an identical fishing season (July - December) in 2005 and 2006 (CA DFW 2011), total regional effort significantly decreased between these two years. The stable effort between 2004 and 2005, despite a decrease in the season length from 9 to 5 months, also seems to support the conclusion that season length is not directly 
correlated with total regional fishing effort. However, for 2004 and 2005 the relationship between season length and fishing effort is confounded by a relaxation of the depth restrictions for take of recreational rockfish. Beginning in 2005, recreational take was allowed in depths up to 40 fathoms rather than the previous maximum depth of 20 fathoms (CA DFW 2011), greatly expanding the available fishable habitat. If maximum fishable depth is a consistent driver of total regional fishing effort, we would expect stable effort once the 40 -fathom depth restriction was implemented in 2005 , rather than the highly variable patterns seen.

The complex year-to-year variation in regional fishing effort is likely due to a combination of the above management restrictions as well as local economic conditions and annual oceanographic variability, but may also be affected by prior management and the composition of the local fleet. In addition to the RCA closures in 2002, the San Simeon Landing closed in the early 2000s (CPFV Focus Group 2014). Prior to its closure, this port was an important source of fishing effort in the northern region of the study area because the landing allowed for nearshore short-range trips in the including Cambria, San Simeon, and Piedras Blancas areas (CPFV Focus Group 2014). The combination of the RCA closures and the loss of the San Simeon landing likely impacted the pre-MPA regional fishing effort documented by the Cal Poly CPFV Observer Program. 


\section{Regional Shifts in Fishing Effort}

In this study, we have shown that the distribution and intensity of regional fishing effort has changed substantially between the pre-MPA (2003-2006) and post-MPA (2008 - 2012) time periods. In particular, we have seen a decrease in fishing effort in the northernmost portion of our study area, minor changes in effort distribution and intensity throughout the central and northern portions of our study area, and an marked increase in effort intensity at several fishing locations in the southern portion of our study area. The mixed effects of MPA implementation on fishing effort may be driven by differences in the distribution of high-quality fishable habitat to the north and south of Point Estero.

With the exception of the waters within the MPA closures and the cooling at the northern edge of the study area, our analysis revealed that CPFV captains largely increased fishing intensity in existing effort hotspots rather than shifting the distribution of their effort, likely due to habitat constraints. Rockfish (Sebastes spp.), lingcod (Ophiodon elongatus), and associated species are found almost exclusively in high-relief rocky habitats (Love et al. 2002), which are patchily distributed along the central coast of California (Rick Kvitek, unpublished data). Unlike fisheries that target species distributed more homogenously throughout a fishing region, local fishing effort for local rockfish/lingcod is a priori limited to areas of the coastal zone with appropriate habitat. In the waters north of Point Estero, high-quality habitat is widespread, whereas suitable rocky outcrops are more sparsely distributed south of Estero Bay (CPFV Focus Group 2014). North 
of Estero, fishing intensity remained similar between the pre and post-MPA time periods because there were more individual fishing locations to absorb the regional increase in fishing effort. In the southern portion of the study area, there are 4 main fishing locations; between Morro Bay and the northern edge of the Point Buchon MPA, between the southern edge of the Point Buchon MPA and Port San Luis, right off the coast at Point Sal, and right off the coast at Point Purisma. Because the few available rocky habitats south of Point Estero were already being fished prior to MPA implementation, it is unsurprising that CPFV captains in this region increased effort intensity at existing hotspots rather than shifting effort to new areas.

Conversations with local CPFV operators largely corroborated our findings. CPFV operators concurred that party boat CPFV trips have decreased north of the Piedras Blancas MPA relative to our $2003-2006$ baseline, and that effort intensity has increased at the four main fishing locations in the southern portion of our study region. However, some CPFV operators disputed our observation that post-MPA fishing effort has declined in the area between the southern edge of the Piedras Blancas MPA and the northern edge of the Cambria MPA relative to our pre-MPA baseline. They asserted that this area is still fished with a level of effort similar to that seen prior to MPA implementation, and the observed decrease is due to a change in trip scheduling. Virg's Landing CPFV trips used to fish that area more often during the week, but now do so more frequently on weekends. Since the Cal Poly CPFV Observer Project only 
samples weekday trips, our data may inaccurately suggest a local decline in effort. In order to investigate the impact of weekday sampling on our spatial analysis, we randomly added additional drops to the relevant area and re-ran the hotspot analysis. The effort for each drop was randomly generated and assigned such that the mean effort was $445 \pm 379$ angler*minutes, the average per-drop effort across the entire dataset. While the addition of these drops marginally increased fishing effort in the area, the model still indicated a significant decrease in fishing effort.

While our general conclusions about changes in the spatial distribution and intensity of fishing effort were upheld by conversations with local CPFV operators, it is important to keep in mind that our analysis is limited to CPFV party boat trips and does not account for fishing effort by CPFV charters, private boats, kayakers, divers, or commercial fishers. No fine-scale spatial data exist to account for fishing pressure from these sources, however it is important to keep their unknown contribution to regional dynamics of fishing activity in mind. Fishing Effort with Distance to MPAs

Given the multitude of studies showing fishing the line behavior subsequent to spatial closures, we were surprised to find no effect of distance on the level of fishing effort near the border of any MPA and no discernable relationship between effort intensity and MPA distance either prior or subsequent to MPA implementation. Studies of post-spatial closure fishing pressure often show intense effort near MPA boundaries (Tupper 2006, Kellner et al. 2007, Goñi 
et al. 2008, Stobart et al. 2009, Goñi et al. 2010). Kellner et al. (2007) predicts fishing the line is part of the optimal distribution of fishing effort targeting mobile species near no-take reserves. However, Horta e Costa et al. (2013) found that the habitat associations of targeted species play a major role in the redistribution of artisanal fishing effort after MPA closures. Multiple studies that document fishing the line also note the closure was connected to adjacent fishable waters by a contiguous segment of habitat (Tupper 2006, Kellner et al. 2007), increasing the potential for the effective spillover of adult fishes from the MPA.

The main targets of the south-central CPFV fleet, rockfish (Sebastes spp.) and lingcod (O. elongatus), are long-lived species with small home ranges whose distribution is largely confined to high-relief rocky outcrops scattered along the coast (Love et al. 2002). Their highly specific habitat requirements and long generation times limit the potential for effective spillover, potentially removing the incentive to fish the line over the first several years of MPA implementation. However, continued monitoring of fishing effort during the coming decades may eventually document fishing the line behavior. While the Piedras Blancas MPA entirely encloses the main reef structure, suitable habitat does span the borders of the White Rock and Point Buchon MPAs. Preliminary data from the California Collaborative Fisheries Research Program, which monitors nearshore groundfish populations for the Año Nuevo, Point Lobos, Piedras Blancas, and Point Buchon MPAs, suggests that rockfish stocks at Point Buchon may be increasing (Dean Wendt, unpublished data). If this trend continues, we expect to see spillover of 
adult fishes into nearby fishable waters. Barring further changes to the MPA network design or economic impediments, this spillover may then motivate increased fishing effort at the edges of these MPAs.

\section{Management Implications and Future Work}

The statewide network of MPAs established in 2007 under the auspices of the 1999 California Marine Life Protection Act must be adaptively managed, with periodic review of MPA monitoring studies and reassessment of the MPA network design (MLPA 1999). The majority of this monitoring work focuses on comparing populations of important species and ecosystem function between MPA sites and nearby areas still open to fishing pressure. While these studies provide crucial insight into the effects of MPAs on populations and communities within their boundaries, they necessarily neglect considerations of broader, region-wide effects of MPAs on an important source of revenue and recreation along the central coast.

The RCA closures in 2002 and the nearshore MPAs established in 2007 have affected the recreational fishing dynamics of boats operating out of Morro Bay and Port San Luis. While CPFV operators used to rotate their effort among multiple good fishing spots in order to avoid depleting rockfish and lingcod stocks (CPFV Focus Group 2014), they now fish the remaining open areas with higher levels of effort than they did in the years immediately preceeding MPA establishment. These site-specific increases in fishing effort intensity, combined with increased total regional effort, may negatively impact the remaining 
accessible fish stocks. Given the effort hotspots identified in this study, the next step is to use the fine-scale data on species composition, length, and catch per unit effort collected by the Cal Poly CPFV Observer Program to assess how these changes in fishing pressure have affected a key resource on the Central Coast. These findings will be integral to ongoing adaptive management efforts in California, as well as enhancing our understanding of how spatial closures affect regional stocks of targeted species. 


\section{BIBLIOGRAPHY}

Aburto-Oropeza, O., Erisman, B., Galland, G.R., Mascareñas-Osorio, I., Sala, E., and Ezcurra, E. 2011. Large recovery of fish biomass in a no-take marine reserve. PLoS One 6: e23601. doi: 10.1371/journal.pone.0023601.

Ashworth, J.S., and Ormond, R.F.G. 2005. Effects of fishing pressure and trophic group on abundance and spillover across boundaries of a no-take zone. Biol. Conserv. 121: 333-344. Elsevier. doi: 10.1016/j.biocon.2004.05.006.

California Ocean Science Trust. 2012. Establishing a Baseline and Assessing Spatial and Socioeconomic Change in the California Central Coast Commercial and CPFV Fisheries.

California Department of Fish and Wildlife. 2011. Recreational Season Lengths and Depth Restrictions for Select California Groundfish (2000 - 2011). 13 pp.

California Department of Fish and Wildlife. 2013. Guide to the Central California Marine Protected Areas: Pigeon Point to Point Conception. Available from California Department of Fish and Wildlife, Monterey CA.

Edgar, G.J., and Barrett, N.S. 1999. Effects of the declaration of marine reserves on Tasmanian reef fishes, invertebrates and plants. J. Exp. Mar. Bio. Ecol. 242: 107-144. Elsevier. Available from http://linkinghub.elsevier.com/retrieve/pii/S0022098199000982.

Edgar, G.J., Stuart-Smith, R.D., Willis, T.J., Kininmonth, S., Baker, S.C., Banks, S., Barrett, N.S., Becerro, M. a., Bernard, A.T.F., Berkhout, J., Buxton, C.D., 
Campbell, S.J., Cooper, A.T., Davey, M., Edgar, S.C., Försterra, G., Galván, D.E., Irigoyen, A.J., Kushner, D.J., Moura, R., Parnell, P.E., Shears, N.T., Soler, G., Strain, E.M. a., and Thomson, R.J. 2014. Global conservation outcomes depend on marine protected areas with five key features. Nature 000: 1-13. doi: 10.1038/nature13022.

Federal Regulations. 2014. Electronic Code of Federal Regulations: $\S 660.360$ Recreational fishery-management measures [online]. Available from: http://www.ecfr.gov/cgi-bin/textidx?c=ecfr\&SID=744a32745386a1b46a96323799bca186\&rgn=div8\&view= text\&node $=50: 13 \cdot 0 \cdot 1 \cdot 1 \cdot 1 \cdot 7 \cdot 1 \cdot 5 \&$ idno $=50$.

Follesa, M.C., Cannas, R., Cau, A.A., Cuccu, D., Gastoni, A., Ortu, A., Pedoni, C., Porcu, C., and Follesa M C. 2011. Spillover effects of a Mediterranean marine protected area on the European spiny lobster Palinurus elephas (Fabricius, 1787) resource. Aquat. Conserv. Mar. Freshw. Ecosyst. 21: 564572. doi: 10.1002/aqc.1213.

Goñi, R., Adlerstein, S., Alvarez-Berastegui, D., Forcada, a, Reñones, O., Criquet, G., Polti, S., Cadiou, G., Valle, C., Lenfant, P., Bonhomme, P., Pérez-Ruzafa, a, Sánchez-Lizaso, J., García-Charton, J., Bernard, G., Stelzenmüller, V., and Planes, S. 2008. Spillover from six western Mediterranean marine protected areas: evidence from artisanal fisheries. Mar. Ecol. Prog. Ser. 366: 159-174. doi: 10.3354/meps07532. 
Halpern, B.S., and Warner, R.R. 2002. Marine reserves have rapid and lasting effects. Ecol. Lett. 5: 361-366. John Wiley \& Sons. Available from http://doi.wiley.com/10.1046/j.1461-0248.2002.00326.x.

Halpern, B.S., Lester, S.E., and Kellner, J.B. 2010. Spillover from marine reserves and the replenishment of fished stocks. Environ. Conserv. 36: 268276. Rockefeller Univ Press. doi: 10.1017/S0376892910000032.

Harmelinvivien, M., Ledireach, L., Baylesempere, J., Charbonnel, E., Garciacharton, J., Ody, D., Perezruzafa, A., Renones, O., Sanchezjerez, P., and Valle, C. 2008. Gradients of abundance and biomass across reserve boundaries in six Mediterranean marine protected areas: Evidence of fish spillover? Biol. Conserv. 141: 1829-1839. Elsevier. doi:

10.1016/j.biocon.2008.04.029.

Horta e Costa, B., Batista, M.I., Gonçalves, L., Erzini, K., Caselle, J.E., Cabral, H.N., and Gonçalves, E.J. 2013. Fishers' behaviour in response to the implementation of a Marine Protected Area. PLoS One 8: e65057. doi: 10.1371/journal.pone.0065057.

La Mesa, G., Molinari, A., Bava, S., Finoia, M.G., Cattaneo-Vietti, R., and Tunesi, L. 2011. Gradients of abundance of sea breams across the boundaries of a Mediterranean marine protected area. Fish. Res. 111: 24-30. Elsevier B.V. doi: 10.1016/j.fishres.2011.06.008.

Lester, S., Halpern, B., Grorud-Colvert, K., Lubchenco, J., Ruttenberg, B., Gaines, S., Airamé, S., and Warner, R. 2009. Biological effects within no- 
take marine reserves: a global synthesis. Mar. Ecol. Prog. Ser. 384: 33-46. doi: 10.3354/meps08029.

Love, M., Yoklavich, M., and Thorsteinson, L. 2002. Rockfishes of the Northeast Pacific. University of California Press., Berkeley and Los Angeles, C.A. Mason, J., Kosaka, R., Mamula, A., and Speir, C. 2012. Effort changes around a marine reserve: The case of the California Rockfish Conservation Area. Mar. Policy 36: 1054-1063. Elsevier. doi: 10.1016/j.marpol.2012.03.002.

McClanahan, T.R., and Kaunda-Arara, B. 2012. Fishery Recovery in a Coral-reef Marine Park and Its Effect on the Adjacent Fishery. Conserv. Biol. 10: 11871199.

McClanahan, T.R., and Mangi, S. 2000. Spillover of Exploitable Fishes from a Marine Park and Its Effect on the Adjacent Fishery. Ecol. Appl. 10: 17921805.

Murawski, S.A., Wigley, S.E., Fogarty, M.J., Rago, P.J., and Mountain, D.G. 2005. Effort distribution and catch patterns adjacent to temperate MPAs. ICES J. Mar. Sci. 62: 1150-1167. doi: 10.1016/j.icesjms.2005.04.005.

Powers, J.E., and Abeare, S.M. 2009. Fishing effort redistribution in response to area closures. Fish. Res. 99: 216-225. doi: 10.1016/j.fishres.2009.06.011.

Roberts, C.M., Bohnsack, J.A., Gell, F., Hawkins, J.P., and Goodridge, R. 2001. Effects of Marine Reserves on Adjacent Fisheries. Science (80-. ). 294: 1920-1923. 
Russ, G.R., and Alcala, A.C. 1996. Do marine reserves export adult fish biomass? Evidence from Apo Island, central Philippines. Mar. Ecol. Prog. Ser. 132: 1-9.

Russ, G.R., and Alcala, A.C. 2011. Enhanced biodiversity beyond marine reserve boundaries: The cup spilleth over. Ecol. Appl. 21: 241-250.

Sen, S. 2010. Developing a framework for displaced fishing effort programs in marine protected areas. Mar. Policy 34: 1171-1177. Elsevier. doi: 10.1016/j.marpol.2010.03.017.

Stelzenmüller, V., Maynou, F., Bernard, G., Cadiou, G., Camilleri, M., Crech'hriou, R., Criquet, G., Dimech, M., Esparza, O., Higgins, R., Lefant, P., and Perez-Ruzafa, A. 2008. Spatial assessment of fishing effort around European marine reserves: Implications for successful fisheries management. Mar. Pollut. Bull. 56: 2018 - 2026.

Stephens, J., Wilson-vandenberg, D., Wendt, D., Carroll, J., Nakamura, R., Nakada, E., Reinecke, S.J., and Wilson, J. 2006. ROCKFISH RESOURCES OF THE SOUTH CENTRAL CALIFORNIA COAST : ANALYSIS OF THE RESOURCE FROM PARTYBOAT DATA , 1980 - 2005. CalCOFI Rep 47: $140-155$.

Stevenson, T.C., Tissot, B.N., and Walsh, W.J. 2013. Socioeconomic consequences of fishing displacement from marine protected areas in Hawaii. Biol. Conserv. 160: 50-58. Elsevier Ltd. doi: 10.1016/j.biocon.2012.11.031. 
Stobart, B., Warwick, R., González, C., Mallol, S., Díaz, D., Reñones, O., and Goñi, R. 2009. Long-term and spillover effects of a marine protected area on an exploited fish community. Mar. Ecol. Prog. Ser. 384: 47-60. InterResearch. doi: 10.3354/meps08007.

Tetreault, I., and Ambrose, R.F. 2014. Temperate Marine Reserves Enhance Targeted but Not Untargeted Fishes in Multiple No-Take MPAs. Ecol. Appl. 17: 2251-2267.

Watson, D.L., Harvey, E.S., Kendrick, G. a., Nardi, K., and Anderson, M.J. 2007. Protection from fishing alters the species composition of fish assemblages in a temperate-tropical transition zone. Mar. Biol. 152: 1197-1206. doi: 10.1007/s00227-007-0767-0. 


\section{APPENDIX I.}
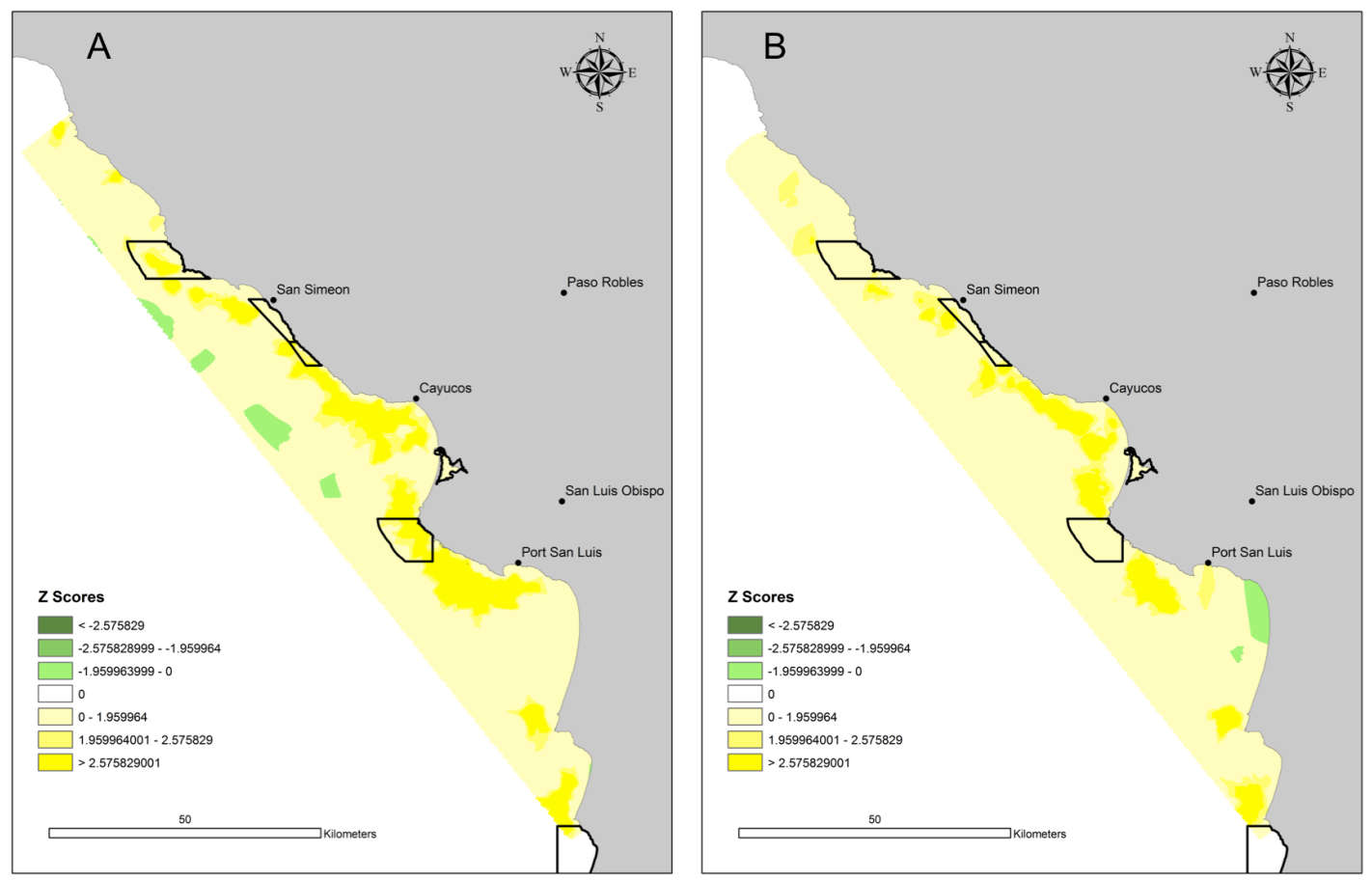

Z-scores for average pre (a) and post MPA (b) fishing effort. Yellow represents pixels with higher effort than the map-wide average, while green represents pixels with lower effort than the map-wide average. The statistical significance of the deviation from the map-wide average is represented by the shade of green or yellow. Dark green and bright yellow represent a statistically significant change at $\alpha=0.01(\mathrm{abs}(Z)>2.575829)$, medium-intensity green and yellow represent a statistically significant change at $0.01 \leq \alpha \leq 0.05(1.959963<\operatorname{abs}(Z)<2.575829)$, pale green and yellow represent no significant change at the $\alpha \leq 0.05$ level $(\operatorname{abs}(Z)<1.959963)$, and white represents pixels with effort equal to the mapwide average. 


\section{APPENDIX II.}
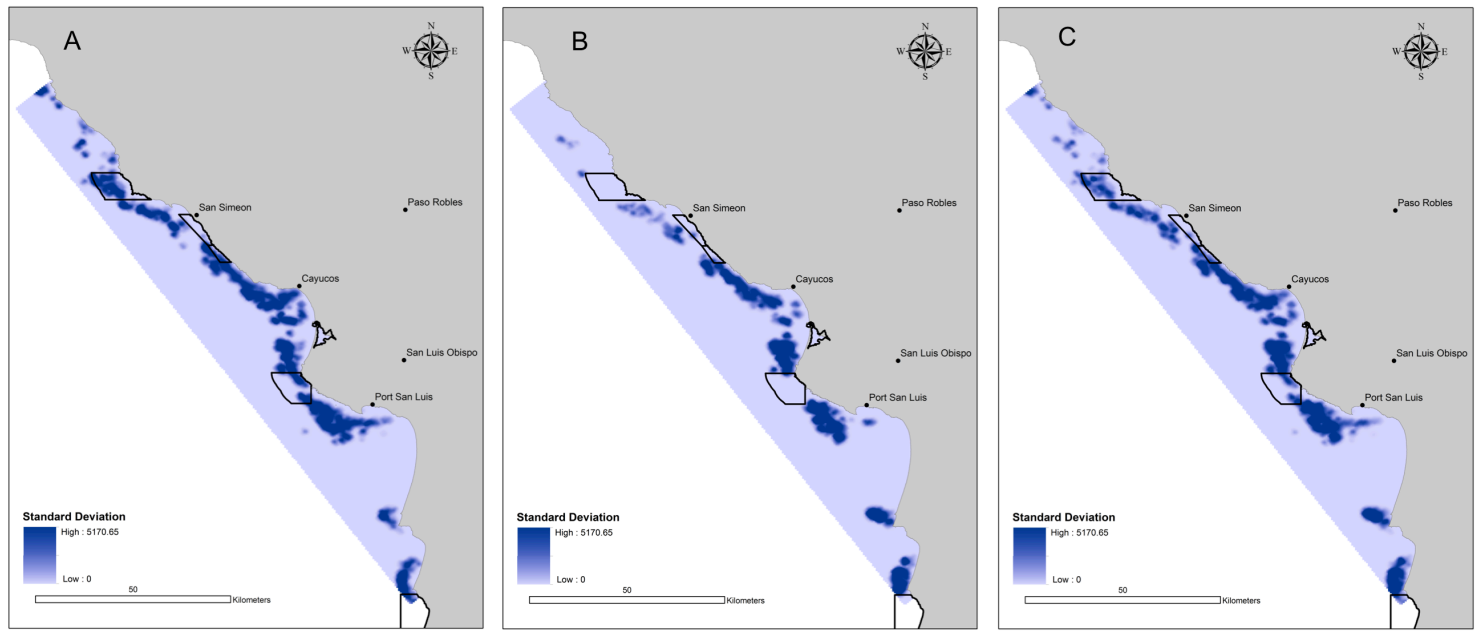

Standard deviation of mean fishing effort estimates. Shown for the pre (a) and post (b) MPA time periods, as well as the difference between pre and post effort (c); calculated across all years and bootstraps. Darker purple represents higher standard deviation values. 